\title{
O Estruturalismo na Teoria das Organizações
}

Fernando C. Prestes Motta*

1. Origens. 2. As Grandes Figuras do Estruturalismo. 3. Idéias Centrais. 4. O Estruturalismo e a Organização. 5. Críticas.

Há dois ou três anos, a palavra estruturalismo foi incorporada ao vocabulário dos grupos mais intelectualizados. Paralelamente, porém, a êsse modismo inconseqüente, houve, realmente, uma verdadeira invasão estruturalista nas ciências sociais, e, muitos especialmente, na lingüística e na antropologia. Coube, provàvelmente, à potencialidade revelada por êsse método no desenvolvimento da lingüística, a responsabilidade por essa invasão nas demais áreas do conhecimento social, isto é, na economia, na sociologia na teoria das organizações, na ciência política e na psicologia . De onde surgiu êsse método?; quais as suas variações?; como se deu sua entrada na teoria das organizações?; quais os seus principais expoentes?; quais as suas teses centrais?; como os estruturalistas vêem a organização?; quais as principais críticas de que vêm sendo alvo? Estas são algumas das perguntas que êste artigo procura responder.

* Professor-Assistente do Departamento de Administração Geral e Relações Industriais da Escola de Administração de Emprêsas de São Paulo, da Fundação Getúlio Vargas.

R. Adm. Emp., Rio de Janeiro, 10(4): 23-41, out./dez. 1970 


\section{Origens}

A palavra estrutura é de emprêgo muito antigo, tanto nas ciências físicas quanto nas sociais e em têrmos amplos significa tudo o que a análise interna de uma totalidade revela, ou seja, elementos, suas inter-relações, disposição. $O$ conceito de estrutura é especialmente importante para a ciência porque pode ser aplicado a coisas diferentes, permitindo a comparação. Nesse sentido, podemos afirmar que o estruturalismo é um método analítico comparativo. Além disso, o estruturalismo considera os fenômenos ou elementos com referência a uma totalidade, considerando, pois, o seu valor de posição. Assim, à sua característica comparativa, podemos acrescentar seu aspecto totalizante. Disto se conclui que para o estruturalismo é de especial importância o relacionamento das partes na constituição do todo, ou seja, que estruturalismo implica em totalidade e interdependencia, já que exclui os conjuntos cujos elementos sejam relacionados por mera justaposição. Simplificando, os conjuntos que interessam ao estruturalista apresentam como característica básica o fato de que o todo é maior do que a simples soma das partes. ${ }^{1}$

Em ciências sociais há várias tradições estruturalistas que podem ser organizadas em quatro grandes grupos, aos quais chamaremos estruturalismo abstrato, estruturalismo concreto, estruturalismo fenomenológico e estruturalismo dialético. Para o primeiro, a estrutura é uma construção informadora do objeto, não se relacionando com a realidade empírica, mas com os modelos construídos em função dela. Nesse sentido, por exemplo, as relações sociais constituiriam a matéria-prima para a construção de modelos que permitiriam a manifestação da estrutura social. Nessa corrente coloca-se Levi-Strauss. Para o segundo grupo de tradições estruturalistas, a estrutura é a definição do objeto. Assim, o conjunto de relações sociais, num dado momento, constituiria uma estrutura. Nessa corrente estão Radecliffe-Brow e Gurvitch. O terceiro grupo, que chamamos estruturalismo fenomenológico, adota a atitude de voltar ao mundo antes que êle seja submetido

1 Pouillon, Jean. Uma Tentativa de Definição. In: Pouillon, Godelier e outros. Problemas do Estruturalismo. Rio de Janeiro, Zahar Editôres, 1968, p. 8 e 9 . 
à determinação da ciência, embora recusando a atitude natural que coloca a existência do mundo em si como objeto. Como afirmou Merleau-Ponty, conhecer é sempre aprender um dado numa certa função, sob uma certa relação, enquanto significa ou se apresenta ao observador tal ou qual estrutura. A compreensão é sempre objetivação. Compreender é aprender objetivamente a significação das intenções do outro a partir de suas condutas. De acôrdo com Raymond Aron, há compreensão quando o conhecimento libera uma significação que, imanente ao real, foi ou poderia ter sido pensada por aquêles que a viveram ou a realizaram. Para o estruturalismo fenomenológico, estrutura é um conjunto que tem um sentido e que oferece, pois, à análise intelectual, um ponto de apoio, mas que ao mesmo tempo não é uma idéia, porque se constitui, se altera ou se reorganiza frente a nós como um espetáculo. Nessa corrente está Max Weber, cujos tipos ideais refletem muito bem essa concepção de estrutura. Cumpre aqui salientar que o tipo ideal não pretende retratar a realidade, à maneira de uma fotografia. Para Weber, nenhum sistema conceitual pode reproduzir integralmente o real e nenhum conceito a diversidade de um fenômeno particular. ${ }^{2} \mathrm{O}$ quarto grupo, a que chamamos estruturalismo dialético, sustenta que a análise que descobre as partes, força-as a preparar seu surgimento ao longo do desenvblvimento do todo, como um episódio de sua história, esfôrço pròpriamente dialético, em que a história garante a análise. Por outro lado, a diferenciação permite pensar a integração, e voltar à totalidade sem fazer uma soma ou uma reunião, pois desde que as partes tenham adquirido bastante autonomia, é pelas relações de reciprocidade que se institui entre elas, que o todo é de algum modo restaurado. Nesta última corrente está Karl Marx. ${ }^{3}$

$\mathrm{Na}$ teoria das organizações as abordagens estruturalistas mais recentes parecem pretender combinar, em proporções que variam de autor para autor, o estruturalismo fenomenológico e o dialético. Sua grande abrangência sintetiza as escolas de administração científica de Taylor e Fayol e de relações humanas de Mayo, mas,

2 Freund, Julien. Sociologie de Max Weber. Paris, Presses Universitaires de France, 1968, p. 53.

3 VIET, Jean. Métodos Estruturalistas nas Ciências Sociais. Rio de Janeiro, Edições Tempo Brasileiro Ltda., 1967, p. 13-27. 
ao contrário do behaviorismo de Barnard e Simon, não se apresenta como um desenvolvimento da segunda e sim como fruto da ruptura que já se esboçava na sua corrente chamada realista. Tal ruptura caracterizou-se nas obras de alguns estruturalistas por uma crítica violenta a uma ideologia que parece encarar o conflito social como patológico e que em seu caráter marcadamente prescritivo e paternalista traz a legitimação da manipulação dos empregados. Assim, a tão decantada participação nas decisões, teòricamente atingível através de discussões democráticas, é, na verdade, uma forma de fazer com que os subordinados acatem decisões prèviamente tomadas, em função de uma ilusão de participação e de poder, geralmente criada pela delegação de autoridade para decidir em assuntos absolutamente indiferentes para a alta cúpula administrativa. Note-se bem que a crítica não se dirige à participação nas decisões, mas sim ao seu caráter ilusório no quadro de referências de relações humanas. Aliás, no que se refere à autêntica participação nas decisóes, é pràticamente indiscutível que, embora tal participação possa atrasar o processo decisório, a rapidez e a melhor qualidade que possibilita à implantação da decisão compensam sua utilização. ${ }^{4}$ Essa crítica violenta e ideológica não é contudo a mais importante que o estruturalismo levantou contra os estudos de relaçóes humanas; mais importante é outra, mais fria e de ordem puramente metodológica, que se refere ao fato dos teóricos de relaçóes humanas haverem-se concentrado em muito poucas variáveis em seus estudos, demonstrando-se incapazes de relacioná-las com outras de grande significação. Para os estruturalistas, a demonstração da inadequação dêsses estudos está nos fracassos freqüentes da aplicação de suas conclusões a casos aparentemente semelhantes. Um exemplo disso está na concentração de atenção, por parte dos teóricos de relaçóes humanas, nos chamados grupos informais, sem nenhuma preocupação com sua importância relativa, com suas relações com os elementos formais e com sua freqüência. Realmente, várias pesquisas recentes têm demonstrado que tais grupos não são importantes no trabalho quanto pretendiam os estudos de relaçóes humanas. ${ }^{5}$

4 Etzioni, Amitai. Political Unification. Nova Iorque, Holt, Rinehart and Winston Inc., 1965, p. 70.

5 Walker, C. R. \& GUEST, R. H. The Man on the Assembly Line. Cambridge, Harvard University Press, 1962. 


\section{As Grandes Figuras do Estruturalismo}

Em certo sentido, a ênfase recente na aplicação de métodos estruturalistas no estudo das organizações pode ser entendida como uma volta às suas origens mais autênticas. De fato, o primeiro teórico significativo das organizações foi Max Weber, que as analisou de uma perspectiva estruturalista fenomenologica, numa linha muito semelhante àquela adotada por Ferdinand Tönnies no nível macrossociológico. Weber deixou inúmeros escritos esparsos que, organizados por sua viúva e por outros cientistas sociais, têm exercido enorme influência no desenvolvimento das ciências sociais e, em particular, da teoria das organizações. Além das várias coletâneas que trazem trabalhos de Weber, como Estrutura de Classes e Estratificação Social, Sociologia da Burocracia e Sociologia Política, trabalhos como Economia e Sociedade, História Econômica Geral, A Etica Protestante e o Espírito do Capitalismo, A Cidade e Ciência e Política: Duas Vocações relacionamse com áreas de estudo que vão desde a sociologia até o urbanismo, passando pela teoria das organizações, pela ciência política, pela história e pela economia. A preocupação central da obra dêsse pioneiro da teoria das organizações parece ser a racionalidade, entendida em têrmos de equação dinâmica entre meios e fins. Seus estudos sôbre poder e burocracia parecem ser tentativas de resposta a perguntas tais como: quais as condiçóes necessárias para o aparecimento da racionalidade?; qual a natureza da racionalidade?; quais as suas consequiências sócio-econômicas? ${ }^{6}$ Nessa linha, nos sistemas sociais altamente burocratizados, o formalismo, a impessoalidade, bem como o caráter profissional de sua administração seriam manifestações de sua racionalidade. ${ }^{7}$

Outros estruturalistas de grande importância na teoria das organizações são Robert K. Merton, Phillip Selznick e Alvin Gouldner,

Vollmer, R. M. Employer Rights and the Employment Relationship. University of California Pres, 1960, p. 75.

Dubin, Robert. Industrial Workers' World. Social Problems, 1956, p. 140. Apud Etzioni, Amitai. Organizações Modernas. São Paulo, Livraria Pioneira Editôra, 1967, p. 76 e 77 .

6 Berlinck, Manoel T. In: Weber, Max. Ciência e Polittica: Duas Vocações. São Paulo, Editôra Cultrix, 1970, p. 10.

7 Bresser Pereira, L. C. Organização Burocrática. In: Balcão, Yolanda F., BREsser PereIRA, L. C., Hopp \& R., Maria Isabel. Organização e Administração. Fundação Getúlio Vargas, em publicação. 
que procurando fugir ao mecanicismo na análise organizacional, tratam de adaptar o modêlo weberiano da burocracia à variável comportamental introduzida na teoria pela Escola de Relações Humanas. Para Merton, a estrutura burocrática introduz transformações na personalidade dos seus participantes que levam à rigidez, a dificuldades no atendimento aos clientes e a ineficiência, transformações essas responsáveis pelo que chama disfunçð̃es ou consequiências imprevistas. Responsável por diversas coletâneas, Merton tem suas idéias expostas nessas e em outras. Além disso, uma obra sua de grande significação e Teoria Social e Estrutura Social. Na mesma linha, Phillip Selznick vê, ao nível da delegação de autoridade, fôrças geradoras de ineficiência na burocracia, através da criação de condiçóes favoráveis à bifurcação de interêsses. Sua obra mais conhecida é Liderança na Administração - Uma Interpretação Sociologica. Além disso, há trabalhos de sua autoria em diversas coletâneas, inclusive em Organizações Complexas, editada por Amitai Etzioni. Alvin Gouldner compõe com Merton e Selznick, o grupo responsável pela descrição do círculo vicioso burocrático. Sua preocupação central é a demonstração do desequilíbrio provocado no sistema pela aplicação de uma técnica de contrôle que vise a manter o equilíbrio de um subsistema e da forma pela qual tal desequilíbrio influi no subsistema inicialmente afetado. Como os demais, Gouldner tem estudos publicados em várias coletâneas, além de livros, entre os quais se destaca Padrões de Burocracia Industrial. Não menos importante que os demais é Amitai Etzioni (da Universidade de Colúmbia) que tem causado um grande impacto na teoria das organizações. Etzioni teve, entre outros, o mérito de chamar a atenção para a importância do método estruturalista na análise organizacional. De forma mais explícita que os anteriores, coloca grande ênfase no papel dos conflitos inevitáveis que ocorrem nas organizações. Seu primeiro livro e talvez o mais importante foi Uma Análise Comparativa das Organizaçóes Complexas, publicado em 1961. Em 1962 publicou 0 Caminho Difícil para a Paz; em 1964, Vencendo sem Guerra, Implicações Domésticas e Internacionais da Corrida Espacial e o conhecidíssimo Organizaçóes Modernas; em 1965, Unificação Política e, muito recentemente, A Sociedade Atuante. Além dêsses livros de sua autoria, Etzioni editou coletâneas de grande relevância para as ciências sociais, tais como 
Mudança Social: Origens, Padrões e Conseqüências, Organizaçб̃es Complexas e Leituras em Organizações Modernas.

Peter M. Blau é outro nome que não pode ser omitido. Suas obras, entre as quais A Dinâmica da Burocracia, A Burocaria na Sociedade Moderna e Organizaçóes Formais, sendo o último em colaboração com W. Richard Scott, da Universidade de Stanford, colocam-no na primeira plana do estruturalismo na teoria das organizações. De especial interêsse é o lugar que confere ao papel dos conflitos no desenvolvimento das organizações, o qual considera um processo fundamentalmente dialético.

Finalmente, não poderíamos deixar de citar Victor A. Thompson, embora não sejam poucos os que o consideram pouco fiel ao método estruturalista. Tal infidelidade é perfeitamente compreensível se considerarmos o passado acadêmico do autor, extremamente relacionado com o behaviorismo. Em que pêse as reservas de ordem metodológica que se possa fazer à sua obra, fica ressalvado o seu caráter profundamente atual, penetrante. Entre seus livros, os mais importantes são Moderna Organização, no qual defende a tese de que a mais sintomática característica da burocracia moderna é o desequilíbrio crescente entre a capacidade e a autoridade, e Burocracia e Inovação, mais recente, no qual demonstra a incapacidade de se desenvolver o potencial criativo na organização burocrática monocrática e advoga o que chama slack-theory, propondo uma administração mais flexível, cuja preocupação com a produção não obscureça a orientação para a inovação.

\section{Idéias Centrais}

\subsection{O HOMEM ORGANIZACIONAL}

Uma sociedade moderna, industrializada, é caracterizada pela existência de um número muito grande de organizações, a ponto de se poder afirmar que o homem passa a delas depender para nascer, viver e morrer. Esse aspecto das sociedades modernas requer um tipo todo especial de personalidade, na qual estejam presentes a flexibilidade, a resistência à frustração, a capacidade 
de adiar as recompensas e o desejo permanente de realização. São estas características que permitem a participação simultânea em vários sistemas sociais, nos quais os papéis desempenhados variam, podendo mesmo chegar à inversão, bem como os desligamentos bruscos de organização e de pessoas e os correspondentes novos relacionamentos sem grandes desgastes emocionais. A flexibilidade torna-se mais do que uma necessidade em um tipo de vida em que tudo se transforma ràpidamente. ${ }^{8} \mathrm{~A}$ grande tolerância à frustração e a capacidade de adiar as recompensas agem como compensações à necessidade que o homem tem de se entregar a tarefas rotineiras na organização, esquecendo-se de preferências e laços pessoais. A mediação dos conflitos que inevitàvelmente surgem como manifestação de um conflito maior entre necessidades organizacionais e necessidades individuais é procurada nas normas racionais, escritas e exaustivas, que pairam sôbre as organizaões como divindades onipotentes. $O$ desejo permanente de realização, por seu turno, garante a conformidade com tais normas, que asseguram o acesso às posições de carreira, estabelecidas em ordem crescente pela alta administração. Desta forma, a cooperação é conseguida em função do desejo intenso de obtenção de recompensas sociais e materiais, o qual também é responsável pela submissão do indivíduo ao processo muitas vêzes doloroso de socialização, que lhe é impôsto pela organização para o desempenho de vários de seus papéis, especialmente daqueles mais especializados. Uma observação importante, que se faz necessária, refere-se ao fato de que as organizações não exigem a presença de tais qualificações maximizadas. Sua complexidade torna úteis composições diversas de personalidade para o preenchimento de seus cargos altamente diferenciados.

A primeira vista, o homem organizacional, dotado de tais características, parece liberto da ética protestante, a qual, segundo Max Weber, tem relação estreita com o espírito de capitalismo moderno. ${ }^{9}$ Tal distanciamento, a nosso ver aparente, vem do fato de que enquanto a personalidade requerida pela sociedade moderna é cooperativa, a ética protestante leva ao individualismo. Pare-

8 Whyte JR., \& William H. The Organization Man. Garden City, Nova Iorque, Doubleday and Company Inc., 1956, p. 435.

9 Weber, Max. A Etica Protestante e o Espirito do Capitalismo. São Paulo, Livraria Pioneira Editôra, 1967. 
ce-nos, entretanto, que algumas das virtudes menores do protestantismo ascético, tais como a laboriosidade, a pontualidade, a integridade, o conformismo e a realização desempenham um papel de enorme relevância na determinação do comportamento do homem organizacional.

$E$ indiscutível que um grande número de pessoas que participam de organizações ressente-se do conformismo exigido. As fôrças que determinam tal conformidade não são, entretanto, tão poderosas, a ponto de impedir a explosão lenta das potencialidades criadoras do homem e o próprio desejo permanente de realização acaba por se constituir em poderoso agente de mudança organizacional. Tal fato apenas vem reforçar o caráter natural e, muitas vêzes, dinâmico, do conflito nas organizações.

\subsection{OS CONFLITOS INEVITÁVEIS}

Tanto a Escola de Administração Científica, quanto a de Relações Humanas, provàvelmente em função de seu tônus prescritivo, colocaram fora de discussão o problema do conflito. A primeira, sustentando que a harmonia de interêsses era natural e a segunda que tal harmonia poderia ser preservada pela administração, através de uma atitude compreensiva e terapêutica, que eliminaria as condutas individuais consideradas aberrantes. Os behavioristas, sem questionar as bases dessa filosofia administrativa, foram um pouco mais longe ao admitir certo nível de conflito entre as necesssidades organizacionais e as individuais, embora permanecendo na análise dos processos, mediante os quais tais conflitos poderiam ser superados pela integração das necessidades individuais às organizacionais, ao estilo do leito de Procusto. Em última análise, tais modos de ver o problema revelam uma atitude profundamente moralista e conservadora, que evita reconhecê-lo em tôdas as suas dimensões, porquanto, em suas manifestações mais violentas, o conflito pode envolver destruição de vidas e produtos culturais, além do fato de se constituir em ameaça constante à estabilidade social..$^{10}$

10 Dubin, Robert. A Sociedade e as Relações entre Sindicatos e Administração. In: ETzıonI, Amitai. Organizações Complexas. São Paulo, Editôra Atlas S. A., 1967. 
Para os estruturalistas contemporâneos da teoria das organizações, o conflito entre grupos é um processo social fundamental. E o conflito o grande elemento propulsor do desenvolvimento, embora isto nem sempre ocorra. Não são portanto, todos os conflitos desejáveis, mas sua existência não pode ser ignorada, já que, sendo inevitáveis, eclodirão sob as mais variadas formas, algumas das quais extremamente violentas. No campo da administração, pode-se afirmar que o conflito entre grupos é inerente às relações de produção, porquanto existindo infinitos procedimentos que visam a tornar o trabalho mais agradável, não se tem notícia de nenhum capaz de torná-lo satisfatório em têrmos absolutos. Preocupados em descobrir a fonte dessa insatisfação do operário moderno, alguns estruturalistas contemporâneos recorrem a Karl Marx e Max Weber. Segundo o primeiro, a mão-deobra da fábrica moderna está alienada de seu trabalho e tal alienação advém, em última análise, de um sistema de propriedade que marginaliza o operariado dos meios de produção. $\mathrm{Pa}$ ra o último, a ausência de propriedade implica também em ausência de contrôle, o que por sua vez implica não só na separação do operário dos meios de produção, como também do soldado dos de combate e do cientista dos de investigação.

Além disso, como bem observou Amitai Etzioni em Organizaçóes Modernas, há na organização tensões inevitáveis, de vários tipos, que podem ser reduzidas, mas não eliminadas. Estas tensões situam-se entre necessidades organizacionais e individuais, racionalidade e irracionalidade, disciplina e liberdade, relações formais e informais, entre níveis hierárquicos e entre unidades administrativas. Merton salienta os conflitos entre burocrata e público, cujas fontes estruturais estão relacionadas com a tendência ao tratamento formal e impessoal por parte do primeiro, quando o que o segundo deseja é uma atenção especial e individualizada. ${ }^{1.1}$ Blau e Scott concentram sua análise da dinâmica organizacional em três dilemas que consideram fundamentais nas organizações, os quais, segundo êles, chamam a atenção para a inevitabilidade do conflito e da mudança. Os três dilemas referem-se a coorde-

11 Merton, Robert K. Estrutura Burocrática e Personalidade. In: Weber, Max e outros. Sociologia da Burocracia. Rio de Janeiro, Zahar Editôres, 1966, p. 108. 
nação e comunicação, a disciplina burocrática e especialização profissional e a planejamento administrativo e iniciativa.

O dilema comunicação-coordenação explica-se pelo fato de que embora o livre fluxo de comunicação tenha um papel importantíssimo na solução dos problemas administrativos, através do alívio das ansiedades geradas pela tomada de decisões que o apoio social proporciona, da percepção e da correção de erros propiciada pela participação de pessoas diferentes e do incentivo às boas sugestões e críticas que a análise grupal oferece. Ele impede a coordenação, já que a comunicação irrestrita cria uma batalha de idéias que torna difícil o acôrdo. Assim, os processos de livre comunicação tornam o desempenho dos grupos superior ao dos indivíduos quando a tarefa é o encontro da solução para um problema, mas inferior quando a tarefa é de coordenação. A diferenciação hierárquica, por outro lado, pode ser altamente eficiente para promover a coordenação, mas é disfuncional para a tomada de decisóes porque interfere no livre fluxo de comunicação.

O segundo dilema entre disciplina burocrática e especialização profissional, também observado por Gouldner em Padrões de Burocracia Industrial, refere-se às oposições existentes entre os princípios que governam o comportamento burocrático e aquêles que governam o comportamento profissional. Há muito em comum entre tais séries de princípios, mas há também muitas diferenças. Assim, enquanto ao profissional cabe representar os interêsses de seus clientes, ao burocrata cabe representar os da organização; enquanto a autoridade do burocrata se baseia em um contrato legal, a do profissional baseia-se no conhecimento que existe de sua especialização técnica. Thompson deu especial destaque a êsse aspecto, afirmando, como já vimos, que a característica mais sintomática da organização moderna é o desequilíbrio crescente entre a capacidade e a autoridade, que no modêlo burocrático se baseia na estrutura hierárquica definida por um sistema formal. ${ }^{12}$ Além disso, as decisões de um burocrata devem ser governadas por uma concordância disciplinada com as diretivas dos seus superiores, enquanto as de um profissional devem sê-lo por padrões profissionais internacionalizados, e, finalmente, quando uma de-

12 Thompson, Victor A. Moderna Organização. Rio de Janeiro, USAID, 1967, p. 13. 
cisão de um burocrata não é bem aceita, o julgamento final cabe à administração, enquanto que, no caso de um profissional, tal julgamento cabe ao grupo dos seus colegas de profissão. As dificuldades que tais diferenças impõem resultam da necessidade que têm as organizações modernas de empregar tanto profissionais quanto burocratas. Gouldner, estudando uma escola superior, focalizou a diferença entre as orientações cosmopolitas dos profissionais e as locais dos burocratas.

O terceiro dilema analisado por Blau e Scott refere-se ao planejamento administrativo e à iniciativa. $O$ avanço tecnológico no mundo moderno exige das organizações um enorme esfôrço criativo, que permita sua sobrevivência e crescimento. Isto quer dizer que o destino das organizações depende em grande medida da iniciativa e da criatividade individual. Entretanto, a necessidade de planejamento persiste e com ela a de contrôle. A maior parte dos mecanismos de contrôle, no entanto, inibem a iniciativa e a criatividade individual. Tal problema é analisado detalhadamente por Thompson em Burocracia e Inovação, no qual propõe a nova estratégia administrativa baseada na slack-theory. Peter Blau e Richard Scott acreditam que tais dilemas são, na verdade, manifestações do dilema maior entre ordem e liberdade. Longe de lastimar tais oposições, porém, êsses autores sustentam que são elas as responsáveis pelo desenvolvimento das organizações. De fato, no processo de resolver problemas antigos, novos problemas são criados, mas a experiência ganha na resolução não é perdida, pois contribui para a busca das soluções para os novos problemas, sugerindo que o desenvolvimento organizacional é um processo essencialmente dialético. ${ }^{13}$

\subsection{OS INCENTIVOS MISTOS}

A forma pela qual foi tratado o problema dos incentivos pelas escolas de Administração Científica e de Relações Humanas é para os estruturalistas a conseqüência de uma visão fragmentada da realidade da organização e da natureza humana. Entendendo organização como um sistema formal, no qual o traba-

13 BLAU, Peter M. \& ScotT, W. Richard. Organizações Formais. São Paulo, Editôra Atlas S. A., 1970, cap. 9. 
lhador tinha um papel absolutamente passivo e a natureza humana como egocêntrica e voltada tão-sòmente para fins econômicos, os incentivos eficientes teriam necessàriamente que ser monetários e tal foi realmente a receita dada pelos teóricos da administração científica. Entendendo a organização como um emaranhado de grupos informais que colaboravam ou não com a administração, na medida em que esta lhes oferecesse ou não status, prestígio e circunstâncias favoráveis ao desenvolvimento da amizade e do companheirismo, a escola de relações humanas, por sua vez, teria que superestimar os incentivos e as recompensas psicossociais. Na verdade, é indiscutível a importância das compensações sociais para a dedicação do homem à organização, não sendo poucos os exemplos de pessoas que trocam empregos por outros menos rendosos, mas que lhes conferem maior prestígio. Tais exemplos são muito comuns entre juízes, que poderiam ganhar muito mais em escritórios de advocacia, entre professôres universitários, que poderiam também ganhar bem mais em emprêsas e mais raros no nível do trabalhador industrial, embora também lá sejam encontrados. Não há dúvidas de que o pleno reconhecimento da importância de tais compensaçóes é um mérito da Escola de Relações Humanas. A grande falha dessa corrente do pensamento administrativo parece estar na condenação dos incentivos monetários. Um levantamento realizado pelo govêrno norte-americano em 514 fábricas que criaram planos de estímulo salarial, mostrou que, em média, a produção aumentou 38,99 por cento e os custos de trabalho decresceram de 11,58 por cento. Em outro caso, um salário diferencial, por hora, de cêrca de 30 por cento, conduziu muitos metalúrgicos a trocar suas tarefas comparativamente não repetitivas, especializadas e autônomas por tarefas de linha de montagem, que não tinham essas qualidades, mas ofereciam melhor remuneração. ${ }^{14}$ Com base em tais considerações, os estruturalistas incluíram em sua análise tanto os incentivos e recompensas psicossociais quanto os materiais, bem como as suas influências mútuas. 14 VITELes, M. S. Motivation and Morale in Industry. Nova Iorque, Nor-
ton, 1953, p. 27 .

WALKER e Guest. The Man on the Assembly Line. Op. cit., p. 91. In: EtzioNI, Amitai. Organizaçōes Modernas, p. 79. 


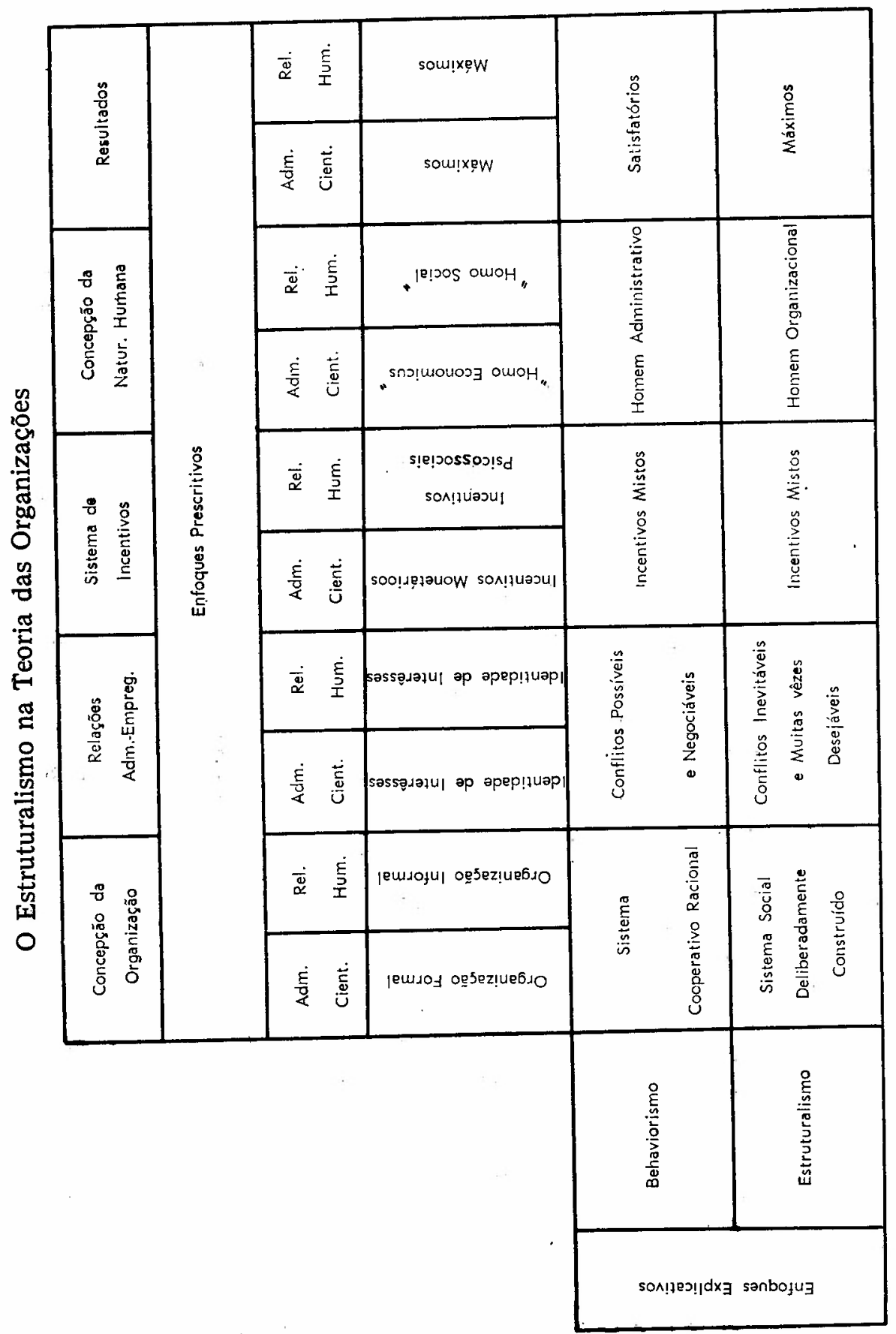




\section{O Estruturalismo e a Organização}

Os estruturalistas vêem a organização como um sistema deliberadamente construído e em constante relação de intercâmbio com seu ambiente. De acôrdo com essa concepção, as relaçóes entre as partes da organização são de grande importância, o que os leva a dar um destaque todo especial às relações entre organização formal e organização informal, seja na análise de emprêsas, escolas, hospitais ou quaisquer outros tipos de organização, dando sempre preferência à abordagem comparativa.

Etzioni, nesse esfôrço de comparação, tomou como base o poder empregado pelos superiores para controlar os subordinados e a orientação dos subordinados com relação a êsse poder. Nessa linha, pôde construir uma tipologia de organizações, na qual se combinam um aspecto estrutural, uma vez que se baseia nos tipos e na distribuição de poder, e um aspecto motivacional, uma vez que se baseia nas diferentes formas de compromisso dos participantes com a organização. $O$ primeiro tipo considerado refere-se às organizações coercitivas, entendidas como aquelas nas quais a coerção constitui o principal meio de contrôle dos participantes dos níveis mais baixos e um alto grau de alienação caracteriza a orientação da maioria dêsses participantes com relação à organização. Exemplos típicos são os campos de concentração, os campos de prisioneiros de guerra, a grande maioria das prisões, instituiçôes correcionais e hospitais de custódia de doentes mentais. $O$ segundo tipo refere-se às organizações utilitárias, isto é, àquelas em que a remuneração é o principal meio de contrôle dos participantes dos níveis mais baixos e o envolvimento calculista caracteriza a orientação da grande maioria dêsses participantes. As emprêsas industriais e comerciais constituem bons exemplos dêsse tipo de organização, embora devamos considerar que elas se aproximarão ou se distanciarão mais do tipo, à medida em que a maioria dos participantes forem funcionários de escritório, profissionais ou operários. $O$ terceiro tipo refere-se às organizações chamadas normativas, isto é, àquelas nas quais o poder normativo é a principal fonte de contrôle dos participantes dos níveis mais baixos e a orientação com relação à organização é caracterizada por um alto nível de envolvimento. Nessas organizações o envolvimento está baseado na 
internalização de diretivas aceitas como legítimas. As organizações religiosas, os hospitais em geral e as universidades são exemplos típicos dêsse tipo de organização. Finalmente, o quarto tipo se refere a organizações que constituem tipos híbridos, ou seja, às organizações duais, tais como sindicatos, unidades de combate, etc. ${ }^{15}$ Segundo Amitai Etzioni, êsses tipos de organizações variam em sua necessidade de coesão. Assim, quando os meios de contrôle são predominantemente coercitivos, como nas prisões tradicionais, a organização não precisa obter o envolvimento dos reclusos, nem, normalmente, é capaz disso; quando os meios normativos predominam, como no caso da maioria das organizações religiosas e educacionais, a organização não pode funcionar efetivamente, a menos que o consenso seja estabelecido e o envolvimento mobilizado e, quando os meios são utilizáveis, tais como nas fábricas, requer-se menos formação de consenso e mobilização do envolvimento do que nas organizações normativas e mais do que nas coercitivas."

Blau e Scott tomam como base, para a construção de sua tipologia, os principais beneficiários das operações da organização. Distinguem, assim, as associações de benefício mútuo, nas quais o principal beneficiário é o quadro social; as firmas comerciais, onde os proprietários são os principais beneficiários; as organizações de serviços, nas quais o grupo de clientes é o principal beneficiado; e, finalmente, as organizações de bem-estar público, onde o principal beneficiado é o grande público. Exemplos típicos de associações de benefício mútuo são os partidos políticos, os sindicatos, os clubes, as organizações de veteranos e as seitas religiosas; de firmas comerciais são as indústrias, as lojas atacadistas e varejistas, os bancos, as companhias de seguros e outras organizações lucrativas; de organizações de serviços, as agências de serviço social, os hospitais, as escolas, as clínicas de saúde, etc.; e de organizações para o bem-estar público, o exército, a divisão de impôsto de renda, o corpo de bombeiros as organizações de pesquisa.:17

I5 Etzioni, Amitai. A Comparative Analysis of Complex Organizations. Nova Iorque, The Free Press, 1968.

16 Etzioni, Amitai. The Active Society. Nova Iorque, The Free Press, 1968, p. 104.

17 BLAU, Peter M. \& Scotr, W. Richard. Organizações Formais. Op. cit., cap. 2. 


\section{Críticas}

As criticas feitas ao estruturalismo têm sido, em sua grande maioria, respostas àquelas formuladas pelos estruturalistas . Nessa linha, Howard Baumgartel, por exemplo, afirma que muita gente confunde relações humanas com ser amável com as pessoas, levando tal amabilidade à displicência para com a realização das tarefas. Para responder a êsse tipo de crítica Baumgartel analisa dois aspectos do problema: em primeiro lugar, lembrando que há um grande volume de pesquisas demonstrando a maior produtividade dos empregados sob a supervisão do tipo relações humanas e, em segundo lugar, o fato de que o esfôrço dos instrutores e administradores em aplicar as conclusões dessas pesquisas no aperfeiçoamento das relações interpessoais no trabalho vai muito além da simples transmissão de como ser amável com as pessoas, visando a desenvolver uma melhor compreensão de como os fatôres humanos envolvem-se na criação de situações nas quais as pessoas podem atingir uma produtividade otima e um sentido de realização. Um outro tipo de crítica que êsse autor considera frequiente é aquela que confunde relações humanas e dinâmica de grupo aplicada com conformidade com a pressão grupal. Para êle êsse tipo de crítica vê relações humanas como o estabelecimento do acôrdo grupal como um objetivo acima de todos os outros, e, portanto, como a colocação da mediocridade acima da valiadde, da qualidade, da correção e da criatividade na solução de problemas. Aqui também analisa o problema sob dois prismas. Em primeiro lugar, lembrando que há pesquisas fidedignas que demonstram que os grupos significativos aos quais uma pessoa pertence exercem maior influência em suas ações e opiniões do que qualquer outra fôrça e, em segundo lugar, da superioridade do grupo em relação ao indivíduo, em têrmos de eficiência, na solução criativa de problemas. Afirma ainda que a Escola de Relações Humanas tem sido acusada de ensinar métodos permissivos de liderança, supervisão e, portanto, de paternalismo. Concorda que as conclusões das pesquisas dessa escola na área de liderança levaram à ênfase no valor dos métodos democráticos, mas sustenta que tais métodos são os mais difíceis de serem observados na prática, além de contrastarem fortemente com o que muitas vêzes é chamado de lide- 
rança laissez-faire. Discordando ainda da crítica de que a Escola de Relações Humanas não admite o conflito, afirma que um estudante bem treinado em relação humana deve conhecer alguma coisa sôbre o mundo que quer ajudar a construir e de como traduzir suas idéias em ações, lutando por elas. Finalmente, com relação ao caráter manipulativo de que a Escola de Relações Humanas é acusada pelos estruturalistas, sustenta que a ciencia comportamental vê a interação humana como um processo contínuo de influenciação mútua, constituindo a sociedade os limites de tentativas de influenciação e que os cursos de relações humanas não visam mais do que a ajudar as pessoas a usar a inteligencia nesse processo. ${ }^{18}$

Muito conhecida é a resposta de George C. Homans ao artigo As perspectivas de Elton Mayo de autoria de Reinhard Bendix e Lloyd H. Fischer, o qual formulou críticas muitos semelhantes às feitas por Etzioni mais tarde. Em artigo publicado na Review Economics and Statistics, onde também o fôra o artigo de Bendix e Fisher, o não menos conhecido sociólogo contesta as críticas feitas ao trabalho de George Elton Mayo, sob o título Algumas Correções às Perspectivas de Elton Mayo. Afirma, em primeiro lugar, que As Perspectivas de Elton Mayo não se referiam ao primeiro plano: as pesquisas concretas na indústria, realizadas por Mayo, no que foi secundado por outros. Tais pesquisas, segundo Homans, revelaram algumas, não tôdas, determinantes do comportamento dos operários, cuja importância tinho sido apenas intuitivamente apreciada; ante novas pesquisas, mesmo em setores diferentes daqueles em que trabalhava, confirmaram plenamente suas descobertas, por exemplo, no trabalho de William Foot Whyte. No que se refere à argumentação de que a maior parte das pesquisas na Western Electric se relacionou a grupos pequenos isolados, não houve tentativa semelhante em têrmos de fábrica e Mayo jamais afirmou que tal não deveria ser feito.

Finalmente, na qualidade de ex-aluno de Mayo, Homans afirma que Bendix e Fischer estão errados em pontos cruciais da inter-

18 Baumgartel, Howard. Too Much Concern with Human Relations. In: ErzronI, Amitai. Readings on Modern Organizations. Nova Jérsei, PrenticeHall, 1969. 
pretação dada por Mayo aos resultados de suas pesquisas. Bendix e Fischer sustentam, por exemplo, que ao interessar-se pelo modo como a cooperação espontânea pode ser realizada, Mayo distingue entre espontâneo e voluntário. Homans, por outro lado, assegura que espontâneo e voluntário eram exatamente a mesma coisa para Mayo. No que se refere à preferência pela ordem social da Idade Média atribuída a Elton Mayo, Homans lembra que ao fazer a distinção entre sociedade estabelecida e sociedade adaptativa, o pai da Escola de Relações Humanas teve o cuidado de salientar que qualquer sociedade que possamos analisar presentemente estará em fase de rápida mudança, consistindo o problema em atingir a cooperação espontânea em uma sociedade que não puder deixar a cooperação entregue à tradição. Além destas, como resposta de grande importância, Homans assegura que Mayo jamais condenou todos os tipos de conflito. Raciocinava, isto sim, não em têrmos absolutos, mas em valôres relativos. Achava que, quantitativamente, havia em nossa civilização conflitos não solucionados suficientes para possibilitar o perigo de um colapso rumo à Idada Média. ${ }^{n 9}$

A despeito dessas reações mais ou menos violentas, a contribuição do estruturalismo à teoria das organizações parece indiscutivel pela consolidação da incorporação iniciada pelos behavioristas, dos estudos de outros tipos de organizações, que não as emprêsas, bem como pela ênfase nova nas relações entre as partes da organização, tais como grupos e outros elementos formais e informais, os vários níveis hierárquicos, as recompensas e incentivos sociais e materiais, além do destaque dado às relações entre a organização e seu ambiente, que preparou o campo para a análise baseada na teoria geral dos sistemas abertos.

19 Homans, George C. Algumas Correções às Perspectivas de Elton Mayo. In: ETZIONI, Amitai. Organizações Complexas, op. cit. 